\title{
Macro Study of Global Electric Vehicle Expansion
}

\author{
Thakur Dhakal ${ }^{\star}$ \\ Postdoctoral Researcher, thakur_dhakal2003@kangwon.ac.kr \\ Kyoung-Soon Min \\ Doctoral Student, ksm@kangwon.ac.kr
}

Department of Industrial Engineering, Kangwon National University, Chuncheon Si, South Korea

\begin{abstract}
Whis study analyzes the diffusion of battery electric vehicles (BEV) in the world and evaluates vehicle charging stations based on the European Union (EU) scenario. Initially, the global BEV sales data from 2005 to 2018 were fitted with the two most frequently used econometric logistics and Bass diffusion models. Further, the study identifies the different stage adopters, forecasts the consumption of BEVs, and examines the velocity and acceleration of BEV diffusion.

Finally, future charging stations are examined to meet the $\mathrm{BEV}$ sales demand. The results suggest that the adoption of BEVs demonstrates a better fit on the Bass model where the global BEV market is estimated to grow from 5,318,850 units in 2019 to $39,996,720$ units by 2030 , and with the reference of the EU countries' adoption scenario, the global charging stations will be increased from 2,084,000 units in 2019 to 9,999,000 units by 2030 .
\end{abstract}

Keywords: business; innovation; diffusion; potential market; electric vehicle
Citation: Dhakal T., Min K.S. (2021) Macro Study of Global Electric Vehicle Expansion. Foresight and STI Governance, 15(1), 67-73. DOI: 10.17323/2500-2597.2021.1.67.73

* corresponding author 
$\mathrm{E}$ lectric Vehicle (EV) technology is one of the most rapidly growing innovations. The development of the technology and its introduction to the market is a continuous process. The adoption process is not permanent and stable and is subject to analysis through innovation diffusion research. In the diffusion process, a fraction of potential users are the first users who adopt the product and they play a decisive role in triggering the diffusion process [Mahajan et al., 1990]. Relative advantage, compatibility, trialability, observability, and complexity are the essential characteristics of diffusion. The diffusion of innovation follows five different stages as innovators, early adopters, early majority, late majority, and laggards [Rogers, 1983]. Different stages of innovation diffusion and corresponding market share are summarized in Figure 1.

Over the last decade, green vehicle technology has grown in popularity among policymakers, consumers, and automobile manufacturers. An outstanding curiosity in every stakeholders' mind is how the electric vehicle will be adopted by consumers. Analyzing the adoption pattern and different stages of diffusion provide benefits for green vehicle industrial stakeholders. The vehicle manufacturers and their distributors' strategic plans would involve less uncertainty. Electric utilities can be better planned for the additional demand brought by electric vehicles (EVs). Policymakers can predict the impact upon government incentives and set national environmental targets [Mahmoudzadeh Andwari et al., 2017]. In recent years, EVs have been one of the most innovative products in the automotive industry [Al-Alawi, Bradley, 2013].

EVs consist of BEVs and plug-in hybrid EVs (PHEVs) [Daziano, Chiew, 2012; Nezamoddini, Wang, 2016; Rezvani et al., 2015]. The overall sales of EVs are steadily rising [Hertzke et al., 2018]. This paper compares the widely used Bass and logistic econometric diffusion model parameters of battery electric vehicle (BEV), suggests the different stages of adopters, and forecasts the future consumption of BEVs until 2030. Further, we analyze the diffusion speed and acceleration of BEV adoption using the Bass function and the average BEV charging points from the reference of present European Union (EU) adoption.

\section{Background}

EVs are a feasible and sustainable solution for the future of technology in the automobile industry, which can reduce the current dependence on fossil fuels and greenhouse gas (GHS) emissions [Adnan et al., 2017; Liao et al., 2017]. EVs have a long history after Joseph Henry first introduced the DCpowered motor in 1830, professor Stratingh built the small model electric car in the Dutch town of
Groningen in 1835. Moses Farmer first introduced the two-passenger EV in 1847. EVs were not viable because they did not have rechargeable electric cells (batteries) at that time. Frenchmen Gaston Plante and Camille Faure respectively designed (1865) and improved (1881) the storage capacity, then the new era for EVs began [Bansal, 2017] but commercially, the EV called Toyota Prius was first introduced worldwide in 2000 [Dijk et al., 2013].

Diffusion studies were introduced in the 1960s [Arndt, 1967; Bass, 1969; Mahajan et al., 1990; Vinet, Zhedanov, 2010]. Then a number of researchers had contributed to the study of diffusion. Diffusion modeling is a useful tool for understanding growth and to estimating future demand [Rao, Kishore, 2010]. The diffusion of innovation follows an S-curve pattern [Fisher, Pry, 1971]. This study conducts a macro study of the diffusion of EVs with two S-shaped growth Bass and logistic models.

Various factors such as the rapid reduction in the cost of batteries, a rise in gasoline prices, customer's awareness, government policies, operation cost, and others cause the rapid diffusion of greener and cleaner EVs [Åhman, 2006; Liu et al., 2013; Rezvani et al., 2015; Scrosati et al., 2015; Wansart, Schnieder, 2010]. However, due to range anxiety, long charging time, and insufficient and inconvenient charging infrastructure, the adoption of EVs remains challenging [Shen et al., 2019]. EVs are the best alternative for ecological reasons. The substitution of the conventional vehicle will be possible if EVs can subvert social and spatial inequalities and if the price of the vehicle can be controlled [Ortar, Ryghaug, 2019]. There are limited research studies that considered EV adoption and diffusion, but comparing and fitting with econometric diffusion models, estimating diffusion speed and acceleration, and forecasting using their diffusion parameters have not yet been studied. This paper aims to address those gaps considering the total BEV adopters from 2005 to 2018 with data extracted from a BNK securities (2019) report. The details of BEV adoption by the country that reported based on their previous releases and IEA data [IEA, 2019] by BNK securities in 2019 are presented in Table 1.

\section{Theoretical Models}

In this study, information diffusion epidemic contagion- logistic and mixed contagion- Bass diffusion models [Frank, 2004] are considered to analyze the diffusion of global BEVs. A brief explanation of the models is presented in this section.

\section{Bass Model}

A useful model for examining adoption patterns and forecasting the demand for new technology is the 
Bass diffusion model [ $Z h u, D u, 2018]$. The mathematical expression of the S-shaped Bass diffusion model [Bass, 1969] when each adopter buys only one unit of new product and market potential does not change over time is presented below:

$N(t)=m\left[\frac{1-e^{-(p+q) t}}{1+\frac{q}{p} e^{-(p+q) t}}\right]$

where is the coefficient of innovation, is the coefficient of imitation, $t$ is the time, is the total number of ultimate (potential) adopters by time $t$, and $N(t)$ is the cumulative numbers of adopters by time $t$. The coefficients $p$ and $q$ both are time-dependent variables.

\section{Logistic Model}

In this study, we used the Griliches logistic model [Griliches, 1957] that also follows an S-shaped sigmoid function. The cumulative adopters $N(t)$ of the innovation in logistic growth is expressed as in equation 2.

$$
N(t)=\frac{m}{1+e^{-(a+b t)}}
$$

where $m$ is the potential adopters, $a$ is the location or timing variable, $b$ is the growth rate in the number of users relative to the proportion of agents who have not yet adopted the EV and $t$ is time.

The logistic function performs symmetrically about its inflection point so that the maximum diffusion growth rate $(\mathrm{mb} / 4)$ is reached when half of the maximum number of adopters $(N(t)=m b / 4)$ has adopted the new technology.

\section{Figure 1. Stages of Innovation Diffusion}

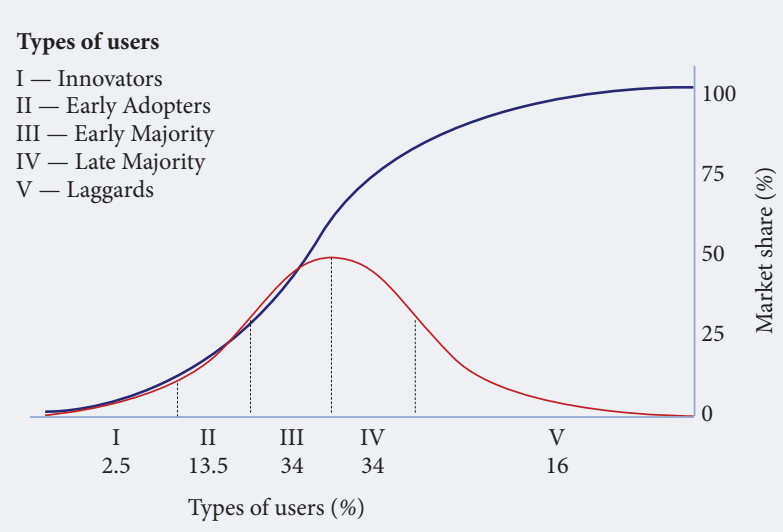

Source: [Rogers, 1983].

\section{Empirical Analysis}

Firstly, we estimated the diffusion parameters of Bass and logistic models using the NLS tool in R-studio. The details of the parameters are presented in Table 2. While fitting the Bass and logistic model with the global BEV adopters with data from 2005 to 2018, the residual standard errors are 24.18 and 24.84, respectively. We have chosen the Bass model as the best-fitted model for BEV adoption. According to the Bass growth, the potential adopters of BEV are $4.07 \mathrm{E}+04$ and the coefficients of innovation and imitation are 2.52E-05 and 0.538 respectively, and adoption due to imitation is highly significant with a $99.9 \%$ confidence interval.

Table 1. BEV Adoption by Country (in thousands)

\begin{tabular}{|c|c|c|c|c|c|c|c|c|c|c|c|c|c|c|}
\hline Country & 2005 & 2006 & 2007 & 2008 & 2009 & 2010 & 2011 & 2012 & 2013 & 2014 & 2015 & 2016 & 2017 & 2018 \\
\hline Australia & & & & & & & 0.05 & 0.22 & 0.41 & 0.78 & 1.54 & 2.21 & 3.42 & 5.22 \\
\hline Brazil & & & & & & & & & & 0.06 & 0.12 & 0.25 & 0.32 & 0.4 \\
\hline Canada & & & & & & & 0.22 & 0.84 & 2.48 & 5.31 & 9.69 & 14.91 & 23.62 & 46.28 \\
\hline Chile & & & & & & & 0.01 & 0.01 & 0.02 & 0.02 & 0.03 & 0.05 & 0.17 & 0.28 \\
\hline China & & & & & 0.48 & 1.57 & 6.32 & 15.96 & 30.57 & 79.48 & 226.19 & 483.19 & 951.19 & 1767.06 \\
\hline Finland & & & & & & & 0.06 & 0.11 & 0.17 & 0.36 & 0.61 & 0.84 & 1.35 & 2.12 \\
\hline France & 0.01 & 0.01 & 0.01 & 0.01 & 0.12 & 0.3 & 2.93 & 8.6 & 17.38 & 27.94 & 45.21 & 66.97 & 92.95 & 124.01 \\
\hline Germany & 0.02 & 0.02 & 0.02 & 0.09 & 0.1 & 0.25 & 1.65 & 3.86 & 9.18 & 17.52 & 29.6 & 40.92 & 59.09 & 95.15 \\
\hline India & & & & 0.37 & 0.53 & 0.88 & 1.33 & 2.76 & 2.95 & 3.35 & 4.35 & 4.8 & 7 & 10.3 \\
\hline Japan & & & & & 1.08 & 3.52 & 16.13 & 29.6 & 44.35 & 60.46 & 70.93 & 86.39 & 104.49 & 131.02 \\
\hline Korea & & & & & & 0.06 & 0.34 & 0.85 & 1.45 & 2.76 & 5.67 & 10.77 & 24.07 & 53.71 \\
\hline Mexico & & & & & & & & 0.09 & 0.1 & 0.15 & 0.24 & 0.5 & 0.73 & 0.93 \\
\hline Netherlands & & & & 0.01 & 0.15 & 0.27 & 1.12 & 1.91 & 4.16 & 6.83 & 9.37 & 13.11 & 21.12 & 46.18 \\
\hline New Zealand & & & & & & 0.01 & 0.03 & 0.05 & 0.08 & 0.19 & 0.49 & 1.65 & 4.58 & 8.94 \\
\hline Norway & & & 0.01 & 0.26 & 0.4 & 0.79 & 2.63 & 6.81 & 15.01 & 33.1 & 58.88 & 83.1 & 116.13 & 162.27 \\
\hline Portugal & & & & & & 0.72 & 0.91 & 0.96 & 1.1 & 1.29 & 1.97 & 2.78 & 4.67 & 9.1 \\
\hline South Africa & & & & & & & & & 0.03 & 0.05 & 0.17 & 0.27 & 0.33 & 0.4 \\
\hline Sweden & & & & & & & 0.18 & 0.45 & 0.88 & 2.12 & 5.08 & 8.03 & 12.39 & 19.54 \\
\hline Thailand & & 0.01 & 0.01 & 0.01 & 0.01 & 0.01 & 0.01 & 0.02 & 0.03 & 0.04 & 0.05 & 0.06 & 0.08 & 0.28 \\
\hline United Kingdom & 0.22 & 0.55 & 1 & 1.22 & 1.4 & 1.65 & 2.87 & 4.57 & 7.25 & 14.06 & 20.95 & 31.46 & 45.01 & 60.75 \\
\hline United States & 1.12 & 1.12 & 1.12 & 2.58 & 2.58 & 3.77 & 13.52 & 28.17 & 75.86 & 139.28 & 210.33 & 297.06 & 401.55 & 640.37 \\
\hline Others & 0.53 & 0.53 & 0.53 & 0.61 & 0.64 & 0.78 & 3.23 & 7.09 & 12.04 & 20.59 & 35.43 & 49.05 & 71.51 & 106.48 \\
\hline Total & 1.89 & 2.23 & 2.69 & 5.15 & 7.48 & 14.59 & 53.53 & 112.92 & 225.5 & 415.74 & 736.9 & 1198.37 & 1945.78 & 3290.80 \\
\hline
\end{tabular}




\section{Table 2. Comparison of Diffusion Parameters}

\begin{tabular}{|c|c|c|}
\hline Parameters & Bass & Logistic \\
\hline$m$ & $4.07 \mathrm{E}+07$ & $3.61 \mathrm{E}+07$ \\
\hline$a(p)$ & $2.52 \mathrm{E}-05$ & $-9.898^{* * *}$ \\
\hline$b(q)$ & $0.538^{* * *}$ & $0.543^{* * *}$ \\
\hline $\begin{array}{c}\text { Residual standard } \\
\text { error }\end{array}$ & 24.18 & 24.84 \\
\hline $\begin{array}{l}\text { *** Significance at the } 0.001 \text { level. } \\
\text { Source: author's calculation. }\end{array}$ \\
\hline
\end{tabular}

Bass growth with the estimated parameters and the actual adopters of BEV [BNK securities, 2019] are plotted in Figure 2. We can see the Bass fit performers through the unique pattern with the actual adoption of BEV from 2005 to 2019. Similarly, future demand from 2019 to 2030, using the Bass growth parameters obtained in Table 1 is presented in Figure 3. The global BEV market is estimated to grow from 5,318,850 in 2019 to 39,996,720 units by 2030.

The first derivative of the Bass model (equation 1) with respect to time performs as the number of new adopters in a time unit. The dimension of speed is also measured in units per time, i.e., adopters per year. Similarly, the second derivative represents the adoption per square of time, which has the same unit as acceleration. The diffusion acceleration indicates the change in the number of new adopters in the period of time. The BEV adoption speed and diffusion acceleration are further calculated to analyze market fluctuations. The diffusion speed and acceleration, approximated by the first and second difference of $\mathrm{BEV}$ using the Bass diffusion function of the period from 2005 to 2030, are plotted in Figure 4.

The maximum diffusion velocity of BEV will be $5,387,248$ adopters per year in 2023 , and the maxi-

\section{Figure 2. The Fit of the Actual Adopters and the Bass Model}

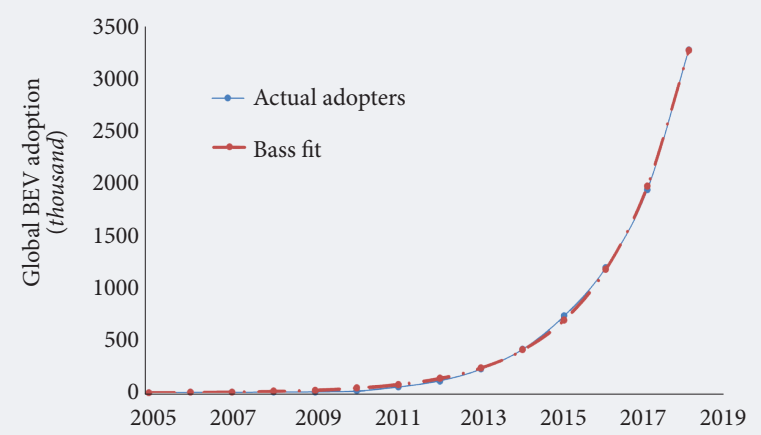

Source: compiled by the author.
Figure 3. Global BEV Demand 2019-2030

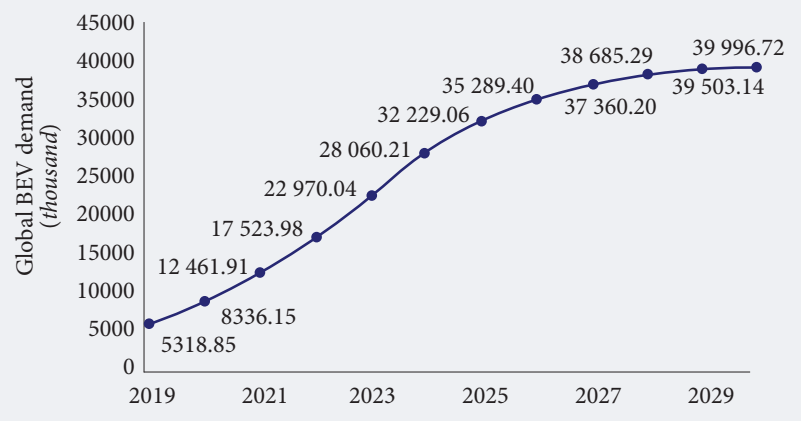

Source: compiled by the author.

mum acceleration will be about 1,134,116 diffusion speed per year in 2020. After 2023, the acceleration of the diffusion will be negative and growing as time passes.

\section{Different Stages of BEV Diffusion}

In 2000, the EVs were commercialized and subsequently BEV sales reached about 1,890 units in 2005 and $3,290,800$ in 2018. As the different milestones in $\mathrm{EV}$ development influence the innovators and early majority, including with imitation effects, BEV technologies are highly and rapidly adopted in the world. Adopters are categorized as innovators, early minority, early majority, late majority, and laggards. The first $2.5 \%$ of the adopters are the innovators, the next $13.5 \%$ are the early adopters, the next $34 \%$ are the early majority, the late majority adopters are the next $34 \%$, and the remaining $16 \%$ are the laggards as shown in Figure 1 [Vinet, Zhedanov, 2010]. Considering the maximum potential number of BEV adopters are about 40,710,000, the timeframes for the different stages can now be calculated. Innovators were the first $1,017,750$ adopters, with

\section{Figure 4. Diffusion Speed and Acceleration} of Global BEV Adoption

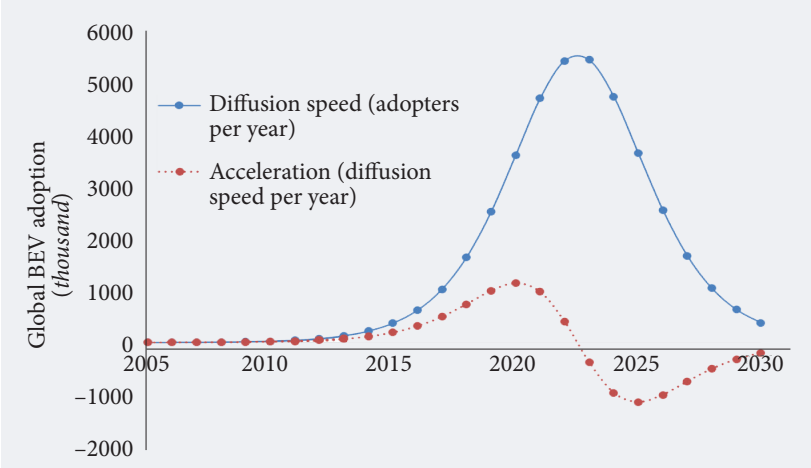

Source: compiled by the author. 


\section{Figure 5. BEV per Charging Point}

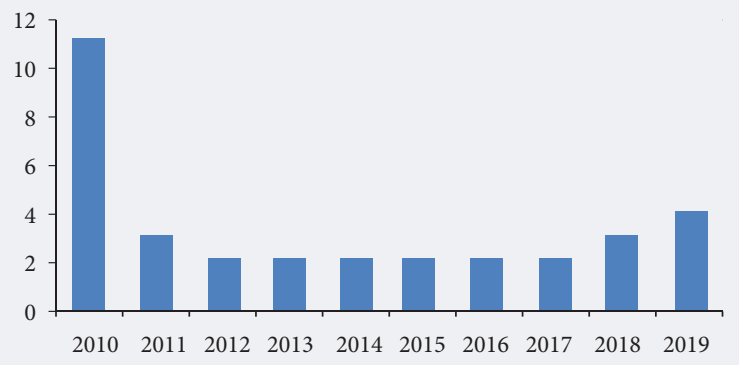

Source: compiled by the author.
Figure 6. The Demand for Public BEV Charging Points (thousands points) this milestone passed in 2016. The next 5,495,850 users who were and will be added from 2016 to 2020 belong to the early adopters. By reaching the milestone of 20.36 million users in 2023, the participation of the early majority accounts for increasing users. Additionally, the increase in the number of $\mathrm{BEV}$ users from 20.36 to 34.2 million in the period 2023-2026 demonstrates the adoption as the late majority. The remaining, those who will adopt after 2026, can be regarded as the laggards.

\section{Demand Forecasting for BEV Charging Points: Evidence From the EU}

In the EU, the average BEVs per public charging point from the reference data observed from 2010 to 2019 is 3.3. ${ }^{1}$ The details of BEVs per charging point in the EU is plotted in Figure 5. In this study, to forecast the demand for BEV charging stations, we have assumed there are four vehicles per charging station based on the scenario of EU countries in 2019.

Further, we forecast future global demand of BEVs based on the Bass diffusion growth model as explained above in section four and the public charging stations scenario in the EU. The detailed demand forecast for global BEV charging stations from 2019 to 2030 is presented in Figure 6.

When four vehicles per charging station and the global BEV adoption follow the Bass growth model, then there will about 10 million public charging stations in the world by the end of 2030 .

\section{Conclusion}

This article studies the adoption and diffusion of BEVs in the world. The global BEV adoption data for 2005-2018 was fitted in the Bass and logistic models using the NLS tool in R-studio. The results show that the Bass model fits the data better than the logistic model. The final potential users of BEVs will be 40.7 million units. In the global scenario, early BEV adopters are active at present. We have forecasted the demand of the global BEV market using the Bass growth model, which is estimated to grow from 5,318,850 in 2019 to $39,996,720$ units by 2030 . Further, we estimated global demand for public charging stations for BEVs, using data for EU countries as a reference, which predicted that number of such station would rise from 2,084,000 in 2019 to 9,999,000 units by 2030 .

For the optimal supply of energy sources, expected socioeconomic changes and future demand for energy must be considered in a timely manner [Filippov, 2018]. Loisel et al. [Loisel et al., 2014] studied electricity demand of BEVs with the highly and slightly decarbonized scenarios and estimated that the total BEV s between 1,107,575 and 4,820,539 units would consume 2,400 MWh in the morning peak hour and 2,700 MWh during evening peak hour in 2030 in Germany. It should be noted that there is an extremely energy-intensive process during the manufacturing of the electric vehicle [Milovidov, 2019]. Without considering such energy consumption, the current study estimates future global demand for BEV charging stations based on the average adoption trends in the EU. The study can be a discussion document for researchers, policy designers, and green energy vehicle stakeholders to design their future research, policies, and sustainable infrastructures. The current study examined the speed and acceleration of BEV adoption on the global market, which the authors did not find in previous research. Such a time-dependent diffusion speed and acceleration study can pave the next path for electric vehicle market research.

However, there are some limitations to this study. First, there are many other diffusion models, but we

https://www.eafo.eu/electric-vehicle-charging-infrastructure, accessed 15.11.2020. 
adopted just Bass and logistic models to examine the diffusion pattern. Second, various factors affect diffusion, which are not considered in this study. Third, we have not made conclusions about the global situation surrounding velocity and acceleration in this study. They are estimated with first and second differentiation of the Bass model. Fourth, the global BEV public charging points may vary within different countries, but this study examined the public charging stations based on the present scenario of the EU.
Future work can address the limitations of the present study, including by analyzing and validating the factors affecting BEV diffusion globally as well as on country basis in order to examine the electricity required to meet future EV demand and in order to estimate impact upon the environment due to increasing EVs. This study focuses on global BEV diffusion. A similar study could also be conducted for individual countries and an estimation of their diffusion driving factors and BEV-related policy formulation studies could be considered in future research.

\section{References}

Adnan N., Nordin S.M., Rahman I., Vasant P.M., Noor A. (2017) A comprehensive review on theoretical framework-based electric vehicle consumer adoption research. International Journal of Energy Research, 3640. https://doi.org/10.1002/er.3640

Åhman M. (2006) Government policy and the development of electric vehicles in Japan. Energy Policy, 34(4), 433-443. https:// doi.org/10.1016/j.enpol.2004.06.011

Al-Alawi B.M., Bradley T.H. (2013) Review of hybrid, plug-in hybrid, and electric vehicle market modeling Studies. Renewable and Sustainable Energy Reviews, 21, 190-203. https://doi.org/10.1016/j.rser.2012.12.048

Arndt J. (1967) Role of Product-Related Conversations in the Diffusion of a New Product. Journal of Marketing Research, 4(3), 291-295. https://doi.org/10.2307/3149462

Bansal R.C. (2017) Electric vehicles. In: Handbook of Automotive Power Electronics and Motor Drives. (ed. A. Emadi), London: Taylor and Francis, 55-96. https://doi.org/10.1201/9781420028157

Bass F.M. (1969) A New Product Growth for Model Consumer Durables. Management Science, 15, 215-227. https://doi. org/10.1287/mnsc.15.5.215

BNK Securities (2019) Detecting new changes and distribution of electric vehicles. South Korea. Busan: BNK Securities (in Korean).

Daziano R.A., Chiew E. (2012) Electric vehicles rising from the dead: Data needs for forecasting consumer response toward sustainable energy sources in personal transportation. Energy Policy, 51, 876-894.https://doi.org/10.1016/j.enpol.2012.09.040

Dijk M., Orsato R.J., Kemp R. (2013) The emergence of an electric mobility trajectory. Energy Policy, 52, 135-145. https://doi. org/10.1016/j.enpol.2012.04.024

Filippov S. (2018) New Technological Revolution and Energy Requirements. Foresight and STI Governance, 12, 20-33. https:// doi.org/10.17323/2500-2597.2018.4.20.33

Fisher J.C., Pry R.H. (1971) A simple substitution model of technological change. Technological Forecasting and Social Change, 3, 75-88. https://doi.org/10.1016/S0040-1625(71)80005-7

Frank L.D. (2004) An analysis of the effect of the economic situation on modeling and forecasting the diffusion of wireless communications in Finland. Technological Forecasting and Social Change, 71, 391-403. https://doi.org/10.1016/S00401625(02)00392-X

Griliches Z. (1957) Hybrid Corn: An Exploration in the Economics of Technological Change. Econometrica, 25(4), 501-522. https://doi.org/10.2307/1905380

Hertzke P., Müller N., Schenk S., Wu T. (2018) The global electric-vehicle market is amped up and on the rise, New York: McKinsey Co.

IEA (2019) Global EV Outlook 2019: Scaling-up the transition to electric mobility, Paris: International Energy Agency.

Liao F., Molin E., van Wee B. (2017) Consumer preferences for electric vehicles: A literature review. Transport Reviews, 37(3), 252-275. https://doi.org/10.1080/01441647.2016.1230794

Liu Y., Klampfl E., Tamor M.A. (2013) Modified bass model with external factors for electric vehicle adoption (SAE Technical Paper), Warrendale, PA: SAE International. https://doi.org/10.4271/2013-01-0505

Loisel R., Pasaoglu G., Thiel C. (2014) Large-scale deployment of electric vehicles in Germany by 2030: An analysis of grid-tovehicle and vehicle-to-grid concepts. Energy Policy, 65, 432-443. https://doi.org/10.1016/j.enpol.2013.10.029

Mahajan V., Muller E., Bass F.M. (1991) New Product Diffusion Models in Marketing: A Review and Directions for Research. In: Diffusion of Technologies and Social Behavior (eds. N. Nakićenović, A. Grübler), Heidelberg, New York, Dordrecht, London: Springer, 125-177 https://doi.org/10.1007/978-3-662-02700-4_6 
Mahmoudzadeh Andwari A., Pesiridis A., Rajoo S., Martinez-Botas R., Esfahanian V. (2017) A Review of Battery Electric Vehicle Technology and Readiness Levels. Renewable and Sustainable Energy Reviews, 78, 414-430. https://doi.org/10.1016/j. rser.2017.03.138

Milovidov V. (2019) Innovations, Sustainable Growth and Energetics: Is Leap of Civilization Possible? Foresight and STI Governance, 13, 62-68. https://doi.org/10.17323/2500-2597.2019.1.62.68

Nezamoddini N., Wang Y. (2016) Risk management and participation planning of electric vehicles in smart grids for demand response. Energy, 116(1), 836-850. https://doi.org/10.1016/j.energy.2016.10.002

Ortar N., Ryghaug M. (2019) Should all cars be electric by 2025? The electric car debate in Europe. Sustainability, 11(7), 1868. https://doi.org/10.3390/su11071868

Rao K.U., Kishore V.V.N. (2010) A review of technology diffusion models with special reference to renewable energy technologies. Renewable and Sustainable Energy Reviews, 14(3), 1070-1078. https://doi.org/10.1016/j.rser.2009.11.007

Rezvani Z., Jansson J., Bodin J. (2015) Advances in consumer electric vehicle adoption research: A review and research agenda. Transportation Research Part D: Transport and Environment, 34, 122-136. https://doi.org/10.1016/j.trd.2014.10.010

Rogers E. (1983) Difussion of Innovations, New York: Free Press.

Scrosati B., Garche J., Tillmetz W. (2015) Advances in Battery Technologies for Electric Vehicles, Amsterdam: Elsevier. https:// doi.org/10.1017/cbo9781316090978.005

Shen Z.-J.M., Feng B., Mao C., Ran L. (2019) Optimization models for electric vehicle service operations: A literature review. Transportation Research Part B: Methodological Volume, 128, 462-477. https://doi.org/10.1016/j.trb.2019.08.006

Vinet L., Zhedanov A. (2010) A “missing” family of classical orthogonal polynomials. Journal of Physics A: Mathematical and Theoretical, 44(8), 085201. https://doi.org/10.1088/1751-8113/44/8/085201

Wansart J., Schnieder E. (2010) Modeling market development of electric vehicles. In: Proceedings of the 2010 IEEE International Systems Conference, San Diego, CA: IEEE, 371-376. https://doi.org/10.1109/systems.2010.5482453

Zhu Z., Du H. (2018) Forecasting the Number of Electric Vehicles: A Case of Beijing. In: IOP Conference Series: Earth and Environmental Science, 170(4), 042037. https://doi.org/10.1088/1755-1315/170/4/042037 